\title{
Correction to: "In Vitro and In Vivo Evidence on the Role of Mitochondrial Impairment as a Mechanism of Lithium-Induced Nephrotoxicity"
}

\author{
Mohammad Mehdi Ommati ${ }^{1} \cdot$ Hossein Niknahad $^{2,3} \cdot$ Omid Farshad $^{2} \cdot$ Negar Azarpira $^{4} \cdot$ Reza Heidari $^{2}$ \\ Published online: 18 August 2020 \\ (C) Springer Science+Business Media, LLC, part of Springer Nature 2020
}

Correction to: Biological Trace Element Research https://doi.org/10.1007/s12011-020-02302-9

The original version of this article unfortunately contained a mistake. The "Funding Information" section is missing.

Funding Information This study was supported by Shanxi Government Scholarship for International Research Assistant (National Natural Science Foundation of China (CN); Grant No. 2018YJ33; provided by Dr. M. Mehdi Ommati), and outstanding doctors volunteering to work in Shanxi Province (No. K271999031; by Dr. M. Mehdi Ommati), Shanxi Province, China.

Publisher's Note Springer Nature remains neutral with regard to jurisdictional claims in published maps and institutional affiliations.

The online version of the original article can be found at https://doi.org/ 10.1007/s12011-020-02302-9

Reza Heidari

rezaheidari@hotmail.com; rheidari@sums.ac.ir

1 College of Life Sciences, Shanxi Agricultural University, Taigu 030801, Shanxi, China

2 Pharmaceutical Sciences Research Center, Shiraz University of Medical Sciences, P. O. Box 1583 71345, Roknabad, Karafarin St, Shiraz, Fars, Iran

3 Department of Pharmacology and Toxicology, Faculty of Pharmacy, Shiraz University of Medical Sciences, Shiraz, Iran

4 Transplant Research Center, Shiraz University of Medical Sciences, Shiraz, Iran 